Bài báo khoa hoc

\title{
Tác động của nước biển dâng do biến đổi khí hậu đến vùng nuôi trồng thủy sản khu vực ven biển Bắc Bộ và Bắc Trung Bộ
}

\author{
Hoàng Ngọc Khắc ${ }^{1,2^{*}}$, Trần Thị Thanh Hải ${ }^{3}$ \\ 1 Viện Nghiên cứu Biến đổi toàn cầu và Phát triển bền vững; hnkhac@hunre.edu.vn; \\ 2 Trường Đại học Tài nguyên và Môi trường Hà Nội; \\ ${ }^{3}$ Viện Khoa học Khí tượng Thủy văn và Biến đổi khí hậu; haitran84@gmail.com; \\ * Tác giả liên hệ: hnkhac@hunre.edu.vn; Tel.: +84-987.8220723
}

Ban Biên tập nhận bài: 10/6/2020; Ngày phản biện xong: 18/7/2020; Ngày đăng bài: $25 / 7 / 2020$

Tóm tắt: Biến đổi khí hậu $(\mathrm{BĐKH})$ hiện nay đang gián tiếp và trực tiếp ảnh hưởng đến đời sống, kinh tế, nông nghiệp đặc biệt tới các quốc gia ven biển. Công tác nuôi trồng thủy sản (NTTS) tại các vùng đồng bằng Bắc Bộ và Bắc Trung Bộ (BB-BTB) đóng vai trò chủ đạo đến thu nhập và lương thực quốc gia. Do đó, việc nhận định đánh giá tình hình phát triển của NTTS tại các khu vực trên dưới các tác động của BĐKH sẽ vô cùng cấp thiết để tìm ra các mô hình chiến lược phát triển ngành đồng thời nhân rộng các mô hình thích ứng này cho các vùng ven biển trên cả nước. Dữ liệu nước biển dâng (NBD) và thực trạng NTTS được tổng hợp nhằm đánh giá nguy cơ tác động của $\mathrm{B} Đ K H$ đến NTTS cho $\mathrm{BB}-\mathrm{BTB}$. Kết quả tính toán 2 kịch bản NBD $50 \mathrm{~cm}$ và NBD $100 \mathrm{~cm}$ cho thấy nguy cơ ngập rất cao (hơn $50 \%$ ) cho các vùng NTTS, đặc biệt là các tỉnh Bắc Bộ như Nam Định, Thái Bình và tỉnh Thừa Thiên Huế. Các tỉnh Bắc Trung Bộ có diện tích NTTS ít bị ảnh hưởng hơn so với vùng Bắc Bộ. Các mô hình NTTS thông minh dần được triển khai nhằm thích ứng với $\mathrm{B} Đ K H$ tại 11 tỉnh thành đang cho thấy bước đầu hiệu quả và những cải thiện đáng kể trong công tác phát triển NTTS.

Từ khóa: Biến đổi khí hậu; Tác động; Nuôi trồng thủy sản; Nuôi trồng thủy sản thông minh.

\section{Mở đầu}

Biến đổi khí hậu cùng với các sự kiện biến động khí hậu như ENSO (El Nino Sounthen Oscillasion) và các sự kiện thời tiết cực đoan - đang ảnh hưởng đến sự phong phú và phân bố nguồn lợi thủy sản, cũng như sự phù hợp về vị trí địa lý đối với các hệ thống NTTS [14]. Theo xếp hạng toàn cầu chỉ số rủi ro do BĐKH (CRI) giai đoạn 1991- 2010 của Tổ chức Germanwatch, 10 quốc gia chịu ảnh hưởng nặng nề nhất của $\mathrm{B} Đ K H$ đều là những nước thuộc nhóm thu nhập thấp và trung bình thấp. Tại khu vực Đông Nam Á, Việt Nam, Indonesia và Philippines là những nước chịu nhiều tác động của $\mathrm{B} Đ K H$, tương ứng theo thứ tự xếp hạng 6, 10, 47 trong bảng xếp hạng toàn cầu CRI giai đoạn 1991-2010 [5].

Đối với lĩnh vực NTTS, nhiều nghiên cứu [6-8] cho thấy BĐKH với các biểu hiện như sự tăng lên của nhiệt độ và mực nước biển, bất thường về chế độ mưa (cả về tần suất và cường độ) và gia tăng các hiện tượng khí hậu cực đoan (bão, áp thấp nhiệt đới...) có tác động trực tiếp hoặc gián tiếp đến các hệ sinh thái và các hệ thống NTTS, từ đó ảnh hưởng đến sinh kế cộng đồng và các vấn đề kinh tế xã hội (Hình 1). Các hiện tượng thời tiết cực đoan như 
rét đậm kéo dài, hạn hán nghiêm trọng, nắng nóng, mưa lớn... xảy ra tại nhiều địa phương trong cả nước, trong đó vùng duyên hải $\mathrm{BB}-\mathrm{BTB}$ là một trong những vùng dễ bị tổn thương nhất do tác động của hiện tượng thời tiết cực đoan.

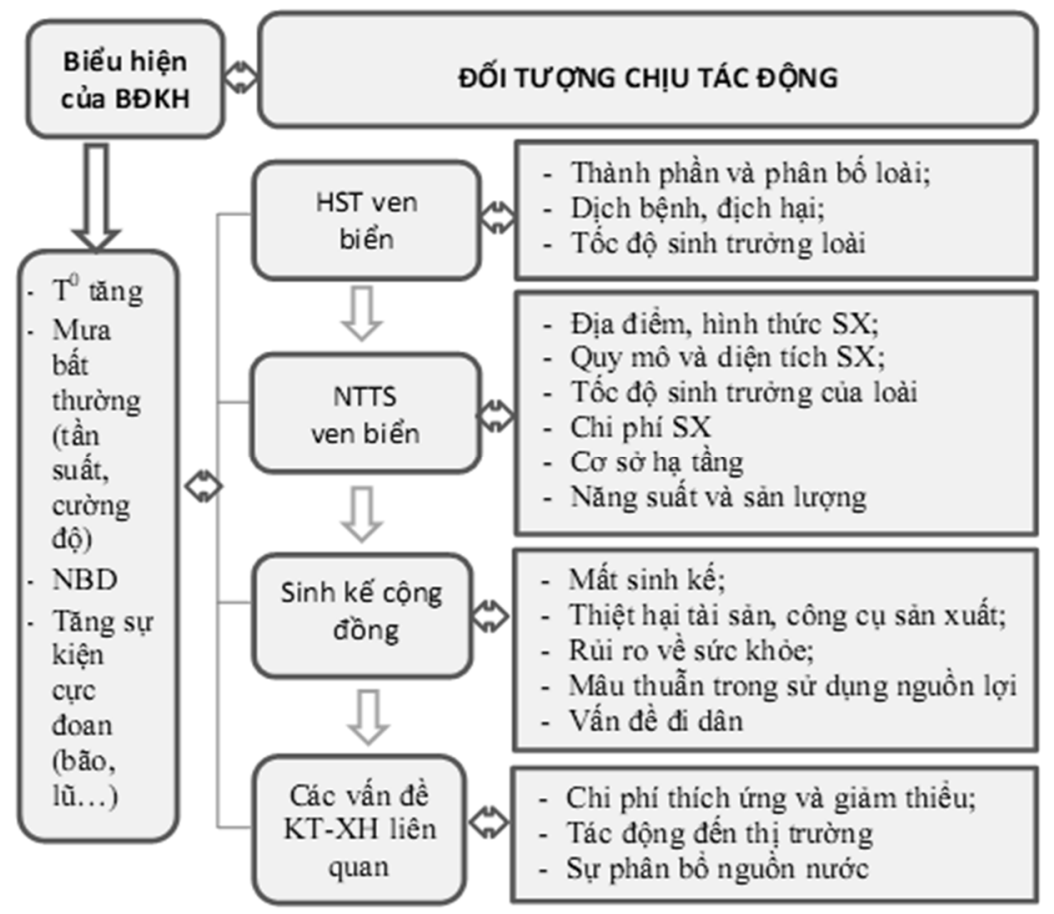

Hình 1. Mối quan hệ tác động giữa BĐKH và NTTS ven biển [8].

Mức độ rủi ro của NTTS dưới tác động của BĐKH có sự khác nhau tùy thuộc vào hệ thống nuôi (ví dụ nuôi kín hay nuôi hở) và đối tượng nuôi (ngưỡng nhiệt độ, độ mặn liên quan đến đặc điểm sinh học). Đối với các hệ thống nuôi hở (ví dụ nuôi nhuyễn thể ở các bãi triều ven biển, nuôi cá lồng biển trên vịnh hoặc ven các đảo) mức độ rủi ro trước các hiện tượng khí hậu cực đoan (bão, tố lốc) và nước biển dâng cao hơn so với các hệ thống nuôi kín (nuôi tôm và cá nước lợ trong ao, đầm phía trong đê...) [9].

Các yếu tố tác động trực tiếp và gián tiếp được đánh giá bao gồm thay đổi nhiệt độ, lượng mưa, các hiện tượng thời tiết cực đoan (lũ, hạn, bão), mực nước biển dâng. Báo cáo của Bộ Tài Nguyên và Môi Trường (2016), mực nước biển tại vùng biển Bắc Bộ có thể tăng lên 2,5 $\mathrm{mm} /$ năm. Với sự tăng lên của mực nước biển, diện tích các vùng có nguy cơ bị xâm nhập mặn và ngập lụt cũng tăng lên nghiêm trọng. Đồng thời, ảnh hưởng đến dòng chảy trong sông, gây xói lở và phá hủy các công trình thủy lợi, đặc biệt là hệ thống NTTS ven biển. Mặt khác, diện tích phát triển NTTS nước lợ ven biển có thể được tăng lên dựa vào mức dâng của mực nước biển.

Tuy nhiên phải đến năm 1997, nghiên cứu quan trọng đầu tiên liên quan đến các tác động của $\mathrm{BĐKH}$ và thủy sản, ngư nghiệp mới được đề cập tới bởi [10]. Mặc dù vậy, bài báo mới đánh giá tác động của BĐKH tới NTTS trên phương pháp sinh lý học, đề xuất giải pháp cho tác động của nhiệt độ tới năng suất [11], phát triển con giống [12] và khả năng sinh sản [13]. Theo đó, [14] đánh giá tác động của BĐKH đến NTTS dựa trên số liệu thu thập về thay đổi khí hậu và xem xét hậu quả của nó đến sự phát triển, tiến hóa của giống loài cũng như sự phân bố của các loài NTTS. Tác động của BĐKH được đánh giá theo thứ tự nhạy cảm của 
con giống đến sự biến động của thời tiết. Trong đó, các loài ở vùng nước lợ, khu vực cửa sông bị ảnh hưởng bởi mực nước biển dâng hoặc sự giảm của mực nước trong sông được đề cập có mức nguy hiểm cao thứ 3 trong bảng xếp hạng.

Đánh giá ảnh hưởng của mực nước biển dâng và hậu quả của nó như xâm nhập mặn đến sản lượng NTTS ở các vùng ven biển nhiệt đới như châu Á với diện tích NTTS lớn, các nghiên cứu dựa vào những ghi nhận ở trạm đo thủy triều ở Việt Nam để kết luận và những bằng chứng của sự dâng lên của mực nước biển: trung bình mỗi năm ở Việt Nam đã tăng trong khoảng 1,75-2,56 mm [15-16]. Bên cạnh đó, Ngân hàng Thế giới xuất bản đã xếp Việt Nam trong nhóm 5 quốc gia chịu ảnh hưởng cao nhất do BĐKH [17]. Theo đó, tại Việt Nam, hai đồng bằng sông Hồng và đồng bằng sông Cửu Long chịu ảnh hưởng nặng nhất. Đồng thời, khi nước biển dâng cao $1 \mathrm{~m}$, ước chừng 5,3\% diện tích tự nhiên, $10,8 \%$ dân số, 10,2\% GDP, $10,9 \%$ vùng đô thị, $7,2 \%$ diện tích nông nghiệp và $28,9 \%$ vùng đất thấp sẽ bị ảnh hưởng [18-19].

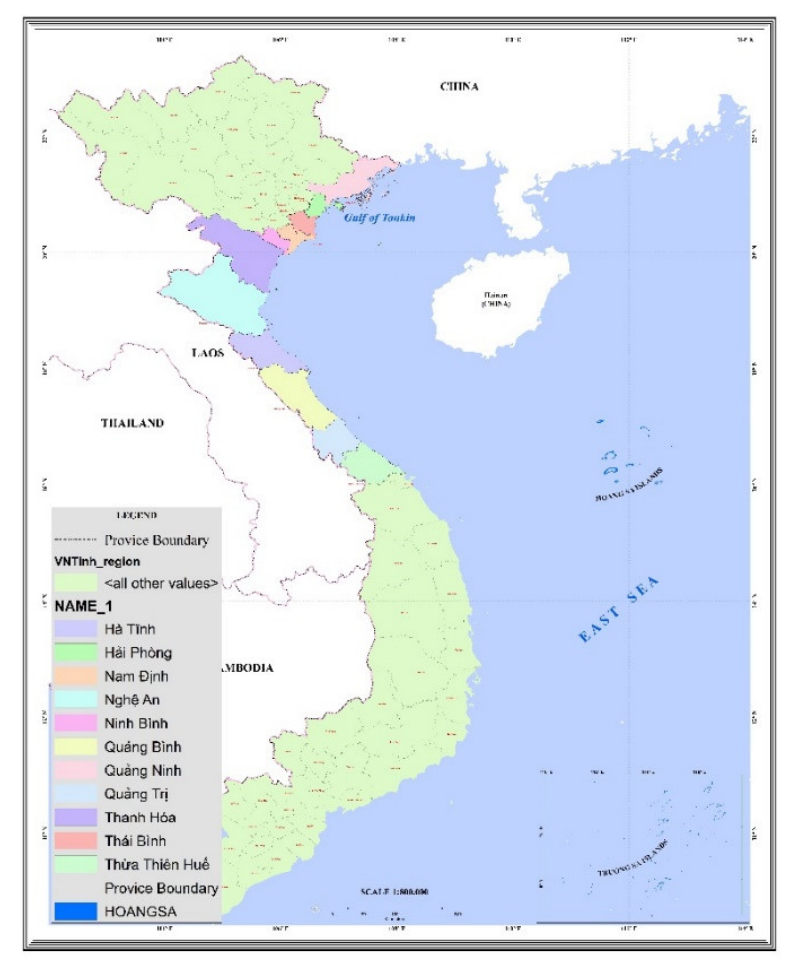

Hình 1. Các tỉnh thành ven biển vùng BB-BTB.

Vùng duyên hải Trung Bộ và Bắc Trung Bộ (TB-BTB) với 11 tỉnh ven biển từ Quảng Ninh tới Thừa Thiên Huế là khu vực phát triển chủ yếu dựa vào nông nghiệp, NTTS (Hình 2). Đây cũng là vùng có sự đa dạng về hệ thống canh tác, phương thức cũng như đối tượng nuôi lớn và đóng vai trò quan trọng đến thương mại và kinh tế-xã hội ở Việt Nam. Vùng duyên hải Bắc Bộ có bãi triều rộng và phù sa dày là cơ sở nuôi trồng thuỷ hải sản, nuôi rong câu và chăn vịt ven bờ. Trong khi đó, khu vực Bắc Trung Bộ có đường bờ biển kéo dài, biển vùng này khá sâu ở sát bờ, nhiều eo biển, cửa sông, vũng, vịnh thuận lợi cho phát triển kinh tế biển du lịch, giao thông biển, đánh bắt cá, phát triển các hải cảng lớn. Vùng biển có nhiều loài cá có giá trị như cá trích, mòi, nhồng (tầng nổi) cá thu (tầng trung), cá mập, mối... (tầng đáy), tạo điều thuận lợi cho phát triển khai thác đánh bắt hải sản.

Theo kịch bản BĐKH của Bộ TN\&MT (2016), duyên hải BB-BTB là một trong những 
khu vực chịu tác động nặng nề bởi $\mathrm{B} Đ K H$, đặc biệt là nước biển dâng. Việc xem xét, phân tích đánh giá tình hình thực trạng của ngành NTTS tại các tỉnh thành $\mathrm{BB}-\mathrm{BTB}$ cũng như các tác động của $\mathrm{BĐKH}$ đến khu vực này trở nên vô cùng cấp thiết trong bối cảnh hướng tới phát triển kinh tế, đảm bảo mục tiêu an ninh lương thực và bền vững môi trường. Do đó, nghiên cứu được thực hiện nhằm phân tích đánh giá mức độ ảnh hưởng của nước biển dâng do $\mathrm{BĐKH}$ cũng như các tác động tiềm tàng và nguy cơ đến đến diện tích NTTS tại các vùng đồng bằng ven biển $\mathrm{BB}-\mathrm{BTB}$.

\section{Phương pháp nghiên cứu và dữ liệu thu thập}

\subsection{Phuoong pháp nghiên cưu}

Bên cạnh việc thu thập đánh giá hiện trạng NTTS tại BB-BTB, diễn biến mực nước biển dâng vùng nghiên cứu được đánh giá và thu thập dựa trên báo cáo $\mathrm{BĐKH} \mathrm{của} \mathrm{Bộ} \mathrm{Tài} \mathrm{Nguyên}$ và Môi Trường cập nhật liên tục tới báo cáo gần nhất năm 2016. Bài báo tiến hành đánh giá tác động của mực NBD theo hai kịch bản $50 \mathrm{~cm}$ và $100 \mathrm{~cm}$ cho toàn bộ vùng nghiên cứu dựa trên việc chồng chập hai lớp thông tin bản đồ gồm bản đồ ngập do nước biển dâng và bản đồ hiện trạng nuôi trồng thủy sản. Công cụ phần mềm ArcGis 10.1 được sử dụng để phân tích chi tiết các kết quả, sơ đồ logic nghiên cứu được thể hiện trong Hình 3.

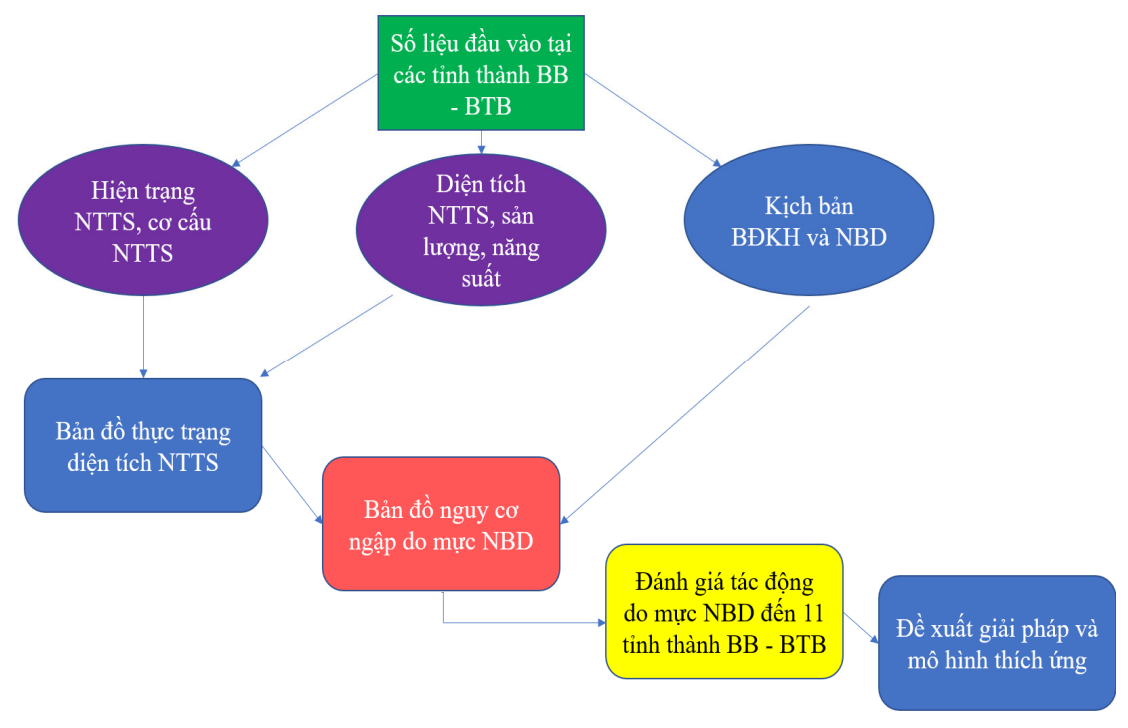

Hình 3. Sơ đồ phương pháp tiếp cận của nghiên cứu.

\subsection{Dũ liệu và hiện trạng khu vục nghiên cưu}

Vùng BB-BTB có đường bờ biển dài $1.200 \mathrm{~km}$, thuận lợi cho việc phát triển nuôi trồng thủy sản nước lợ và nước mặn. Tính trung bình trong 5 năm qua, tổng diện tích nuôi trồng và sản xuất trong khu vực đã tăng lần lượt 1,29\% và $8,23 \%$ [21].

Với mục tiêu đánh giá các tác động của BĐKH đến NTTS vùng đồng bằng ven biển Trung Bộ và Bắc Trung Bộ, các phương pháp áp dụng được thực hiện bao gồm thu thập tổng hợp tài liệu được kế thừa, điều tra thực tế, xử lý phân tích thống kê dữ liệu và tham vấn ý kiến chuyên gia.

Nghiên cứu tiến hành thu thập dữ liệu về thực trạng NTTS vùng nghiên cứu bao gồm cơ cấu NTTS tại các tỉnh, thành và địa phương. Đồng thời, diện tích NTTS tương ứng với các loài và sản lượng cũng như năng suất NTTS qua các năm từ 1995 đến 2018 được thu thập 
nhằm đánh giá hiệu quả và tiềm năng phát triển cũng như nguy cơ tác động của $\mathrm{BĐKH} \mathrm{đến}$ các mô hình NTTS. Từ đó bản đồ diện tích các khu vực NTTS được xây dựng sử dụng phần mềm xây dựng bản đồ ArcGis. Các thông tin địa lý, vị trí, hành chính và hệ thống sông ngòi cũng như vị trí NTTS được thu thập làm cơ sở xây dựng bản đồ thực trạng NTTS.

\section{Kết quả và thảo luận}

Trong nghiên cứu này, tác động do BĐKH đến diện tích NTTS được tập trung đánh giá dựa trên việc xác định diện tích vùng nuôi có nguy cơ ngập do mực nước biển dâng theo kịch bản dâng $50 \mathrm{~cm}$ và $100 \mathrm{~cm}$. Dựa trên thông tin khảo sát về diện tích NTTS ở $\mathrm{BB}-\mathrm{BTB}$ cùng với kịch bản nước biển dâng do Bộ Tài Nguyên và Môi Trường công bố 2016, bản đồ về diện tích NTTS và khu vực có nguy cơ ngập được xây dựng cho từng tỉnh trên địa bàn nghiên cứu. Trong đó khu vực có nguy cơ ngập cao nhất là các tỉnh phía Bắc bao gồm Hải Phòng, Nam Định, Ninh Bình và Thái Bình cho cả 2 kịch bản.

\subsection{Tác động của mục nuớc biển dâng lên tỉnh Hải Phòng}

Diện tích NTTS và nguy cơ ngập do mực nước biển dâng $50 \mathrm{~cm}$ (trái) và $100 \mathrm{~cm}$ (phải) cho các huyện trên tỉnh Hải Phòng (Hình 4). Hải Phòng được đánh giá là tỉnh có mức độ tập trung các cơ sở NTTS cao so với các tỉnh còn lại trong khu vực nghiên cứu với diện tích NTTS ở các huyện hầu hết trên 300 ha, đặc biệt là huyện Tiên Lãng với diện tích NTTS lên đến 1.771 ha. Theo kết quả tính toán, nguy cơ ngập đối với kịch bản NBD $50 \mathrm{~cm}$ tập trung chủ yếu khu vực các huyện phía bắc của tỉnh như Dương Kinh, Hải An, Thủy Nguyên với hơn $10 \%$ diện tích có nguy cơ bị ngập. Trong đó, huyện Cát Hải có nguy cơ ngập lớn nhất với gần 46,7\% diện tích NTTS và tăng lên $51,7 \%$ đối với kịch bản NBD $100 \mathrm{~cm}$. Tuy nhiên, đối với kịch bản NBD $100 \mathrm{~cm}$, kết quả tính toán cho thấy hầu hết diện tích NTTS có nguy cơ ngập trên các huyện tại Hải Phòng đều vượt qua ngưỡng 50\%. Quận Đồ Sơn là khu vực ven biển có khả năng bị ngập cao nhất, đến hơn 77\%, theo sau là quận Dương Kinh với diện tích có nguy cơ ngập lên đến $68,3 \%$.

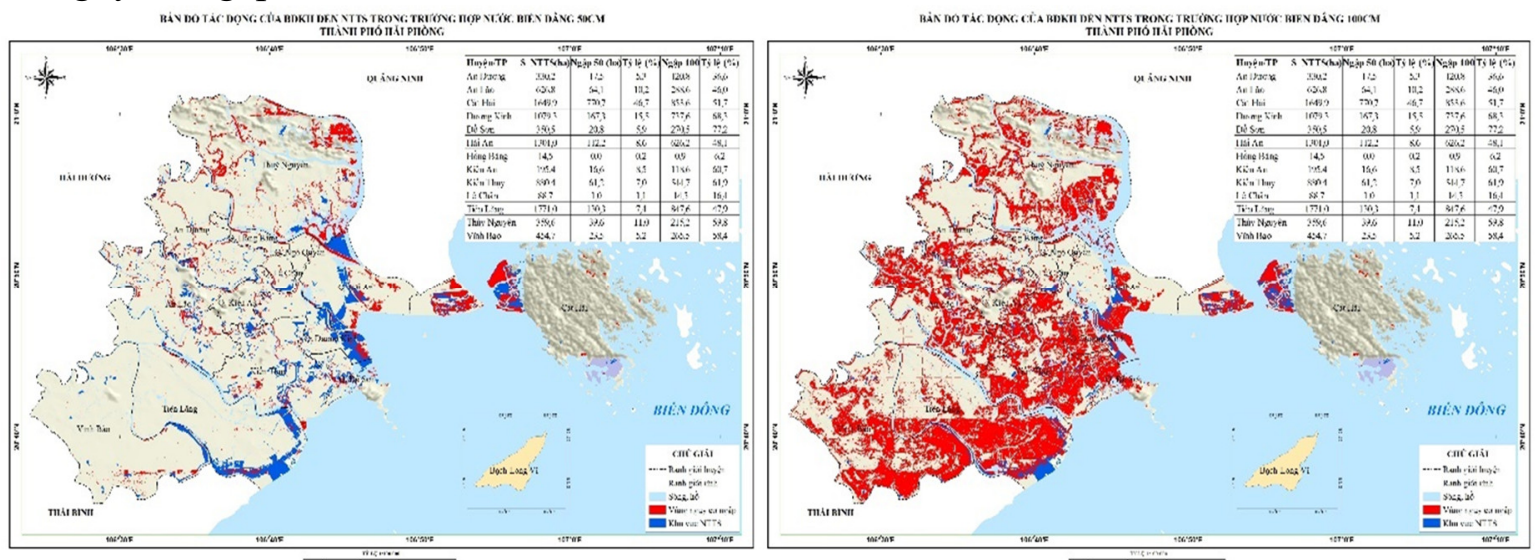

Hình 4. Diện tích NTTS có nguy cơ ngập do NBD $50 \mathrm{~cm}$ (trái) và NBD $100 \mathrm{~cm}$ (phải) tại tỉnh Hải Phòng.

Các huyện có mức tăng đáng kể khác bao gồm Kiến An, Kiến Thụy và Thủy Nguyên với gần $60 \%$ diện tích NTTS có nguy cơ ngập. Mức tăng báo động về tỉ lệ diện tích NTTS có nguy cơ ngập tại các huyện/thành phố trên khu vực tỉnh Hải Phòng khi mực nước biển 
dâng $100 \mathrm{~cm}$ cho thấy đây là vùng nên cần được quan tâm đầu tiên trong bối cảnh BĐKH hiện nay.

\subsection{Tác động của mực nước biển dâng đến tỉnh Nam Định}

Hình 5 thể hiện diện tích có nguy cơ ngập và diện tích NTTS khu vực tỉnh Nam Định qua hai kịch bản NBD.

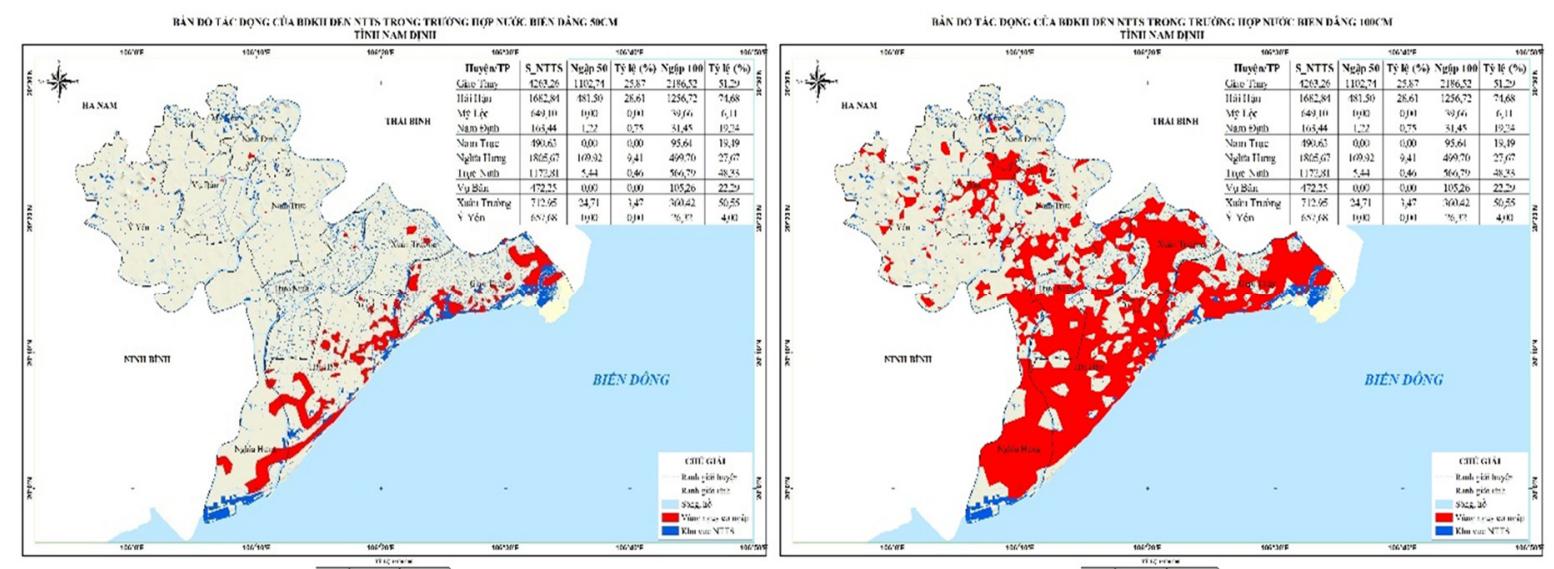

Hình 5. Diện tích NTTS có nguy cơ ngập do NBD $50 \mathrm{~cm}$ (trái) và NBD $100 \mathrm{~cm}$ (phải) tại tỉnh Nam Định.

Với thực tế là khu vực phát triển mạnh về nông nghiệp và đặc biệt là thủy sản, tỉnh Nam Định có diện tích NTTS tương đối đáng kể ở tất cả các huyện, đặc biệt là các huyện ven biển như Giao Thủy, Hải Hậu, Nghĩa Hưng và Trực Ninh. Đây cũng là các huyện có nguy cơ ngập cao nhất so với cả vùng qua hai kịch bản. Với kịch bản NBD $50 \mathrm{~cm}$, diện tích NTTS có nguy cơ ngập cao nhất có thể xảy ra tại Giao Thủy và Hải Hậu với $25,87 \%$ và $28,61 \%$ trong khi vùng có nguy cơ ngập tại Nghĩa Hưng chỉ chiếm khoảng 9,4\%. Các huyện còn lại hầu như không bị ảnh hưởng, hoặc ít như Xuân Trường với khoảng 3,47\%. Tuy nhiên, khi mực nước biển dâng lên $100 \mathrm{~cm}$, toàn vùng đều bị ảnh hưởng nghiêm trọng, đặc biệt là huyện hải Hậu với hơn 74\% diện tích NTTS có nguy cơ ngập. Các huyện như Xuân Trường, Giao Thủy và Trực Ninh cũng có khả năng ngập đến gần $50 \%$.

\subsection{Tác động của mục nước biển dâng đến tỉnh Thái Bình}

Diện tích NTTS có nguy cơ ngập do NBD $50 \mathrm{~cm}$ (trái) và NBD $100 \mathrm{~cm}$ (phải) cho các huyện ở tỉnh Thái Bình (Hình 6). Qua kết quả tính toán có thể thấy, mực nước biển dâng với kịch bản $100 \mathrm{~cm}$ có nguy cơ gây ngập rất lớn cho toàn bộ tỉnh Thái Bình trong khi kịch bản NBD $50 \mathrm{~cm}$ đặc biệt có tác động lớn đến vùng ven biển phía Nam của tỉnh như Tiền Hải, thành phố Thái Bình và huyện Kiến Xương. Hơn 71\% diện tích NTTS có nguy cơ ngập ở thành phố Thái Bình với kịch bản NBD 50cm tương đương với kịch bản NBD $100 \mathrm{~cm}$. Hai huyện Kiến Xương và Tiền Hải có khả năng ngập do NBD 50 cm ở mức 28,65\% và 20,11\%. Các huyện còn lại mặc dù ít bị ảnh hưởng hơn so với ba huyện trên nhưng vẫn ở mức nguy cơ cao với hơn $10 \%$ diện tích vùng NTTS có nguy cơ ngập khi mực NBD chỉ tăng lên $50 \mathrm{~cm}$. 

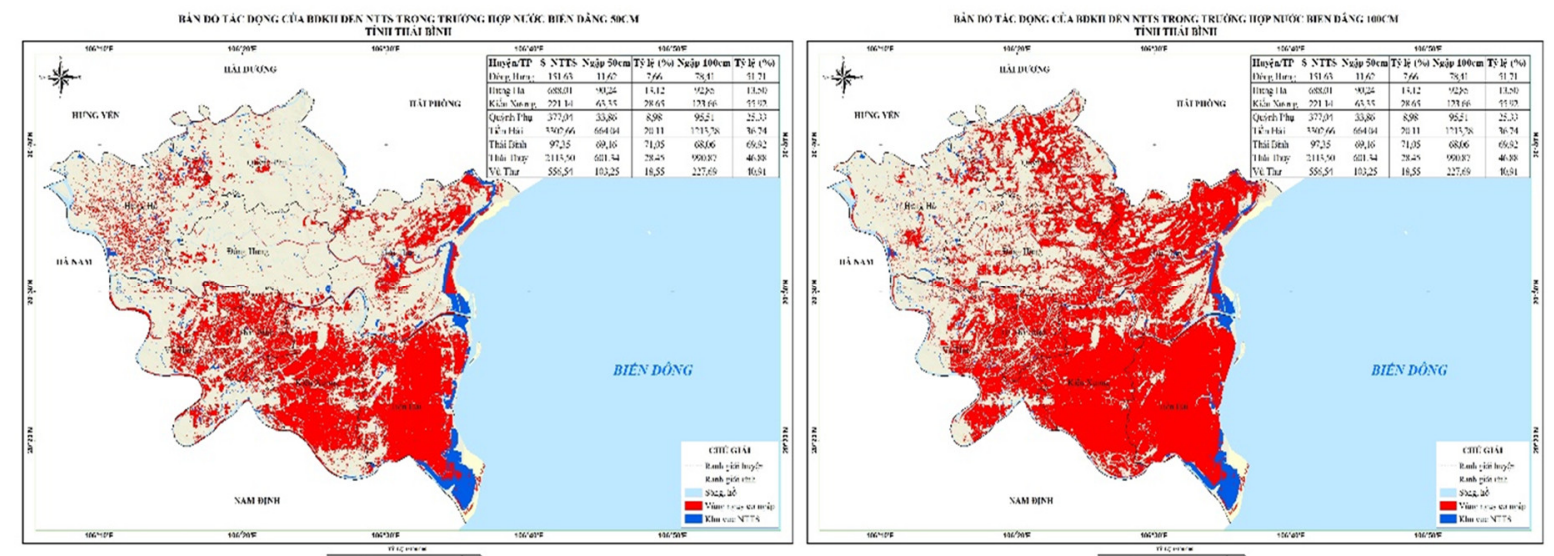

Hình 6. Diện tích NTTS có nguy cơ ngập do NBD $50 \mathrm{~cm}$ (trái) và NBD $100 \mathrm{~cm}$ (phải) tại tỉnh Thái Bình.

Đối với kịch bản NBD $100 \mathrm{~cm}$, tình hình ngập diễn biến phức tạp và trên quy mô lớn khi huyện Đông Hưng vốn có ít khả năng bị ngập với chỉ 7,66\% vùng NTTS ở kịch bản NBD 50 $\mathrm{cm}$, thì tỷ lệ vùng NTTS có nguy cơ ngập ở huyện này lên đến $51,71 \%$. Các huyện như Vũ Thư, Thái Thụy, Kiến Xương và Tiền Hải cũng có mức nguy cơ ngập cao với hơn $40 \%$ đến $55 \%$. Huyện ít có biến động nhất là Hưng Hà với diện tích NTTS có nguy cơ nằm trong vùng ảnh hưởng dao động trong khoảng 13,12\%-13,50\% qua hai kịch bản NBD.

\subsection{Tác động của mực nước biển dâng đến tỉnh Ninh Bình}

Hình 7 thể hiện diện tích NTTS có nguy cơ ngập do NBD $50 \mathrm{~cm}$ (trái) và NBD $100 \mathrm{~cm}$ (phải) trên địa bàn tỉnh Ninh Bình.

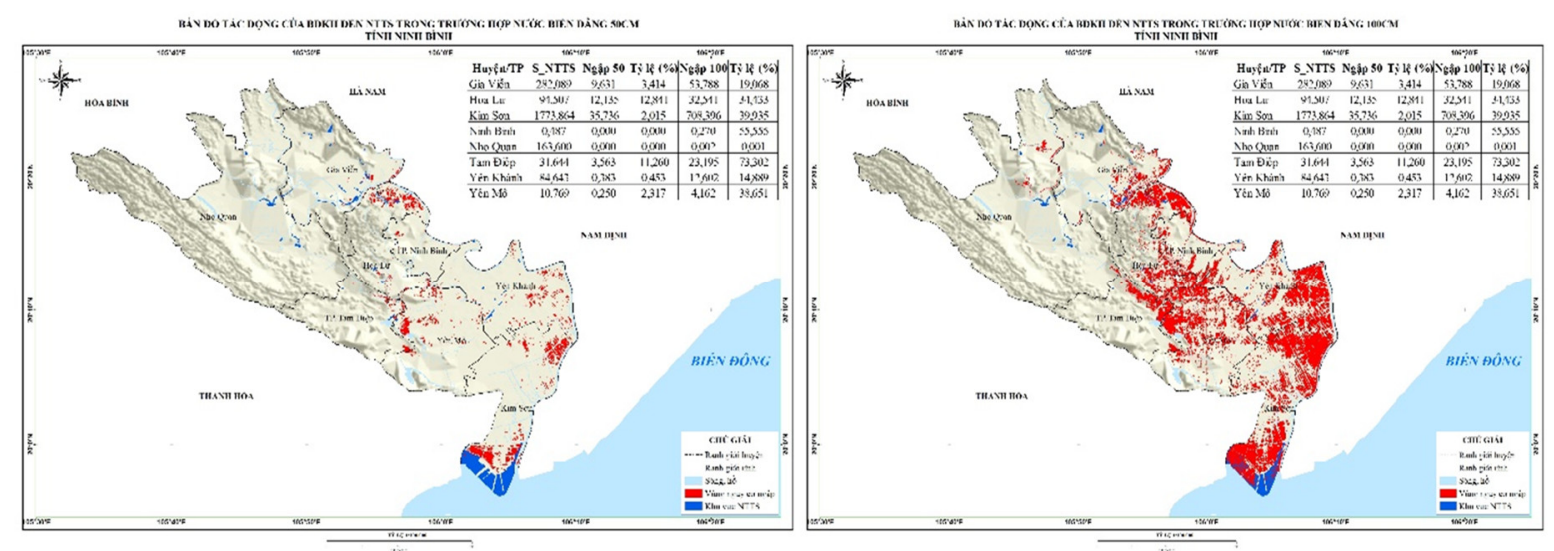

Hình 7. Diện tích NTTS có nguy cơ ngập do NBD $50 \mathrm{~cm}$ (trái) và NBD $100 \mathrm{~cm}$ (phải) tại tỉnh Ninh Bình.

Với diện tích NTTS lớn (gần 1774 ha), huyện Kim Sơn, có nguy cơ ngập lên đến $35 \%$ và gần $40 \%$ đối với kịch bản NBD $50 \mathrm{~cm}$ và NBD $100 \mathrm{~cm}$. Đáng kể nhất ở đây là thành phố Ninh Bình vốn không có nguy cơ bị tác động khi mực nước biển dâng $50 \mathrm{~cm}$, do có diện tích NTTS nhỏ nhất toàn tỉnh nhưng lại có nguy cơ ngập lên đến hơn $55 \%$ đối với kịch bản NBD $100 \mathrm{~cm}$. Bên cạnh đó, thành phố Tam Điệp với diện tích NTTS khoảng 31,64 ha với nguy cơ ngập khoảng 3,56\% khi mực nước biển cao lên $50 \mathrm{~cm}$, cũng đối mặt với khả năng ngập lên tới 73,3\% khi mực nước biển dâng lên $100 \mathrm{~cm}$. Các huyện Kim Sơn, Yên Mô và Hoa Lư có 
mức tăng nguy cơ ngập lên đáng kể ở kịch bản NBD 100 cm với hơn 34,4\%. Huyện Gia Viễn có diện tích NTTS tới 282 ha, đứng thứ ba trong tỉnh Ninh Bình, ít bị ảnh hưởng hơn cả bởi mực NBD với tỷ lệ ngập khoảng 3,4\% ở kịch bản NBD $50 \mathrm{~cm}$ và khoảng $19 \%$ với kịch bản NBD $100 \mathrm{~cm}$. Tương tự, là khu vực có diện tích NTTS nhiều thứ bốn của tỉnh (khoảng 163,6 ha), huyện Nho Quan hầu như không bị tác động bởi nước biển dâng. Điều này có thể được giải thích bởi vị trí địa lý của hai huyện trên khá xa so với cửa biển và có độ cao hơn so với các huyện còn lại.

Các tỉnh vùng Bắc Trung Bộ như Thanh Hóa, Hà Tĩnh, Quảng Trị, Quảng Bình có diện tích NTTS lớn tuy nhiên chỉ tập trung tại một vài huyện ven biển, cho thấy nguy cơ ngập do NBD thấp so với các tỉnh Bắc Bộ. Tỉnh Thừa Thiên Huế, mặc dù có diện tích NTTS lớn tập trung ở bốn huyện ven biển, mặc khác cho thấy nguy cơ ngập cao đối với cả hai kịch bản NBD với hơn 53\% đến 83,8\% (NBD 100 cm tại huyện Quảng Điền).

\section{Kết luận}

Kết quả đánh giá tác động của BĐKH đến NTTS ven biển khu vực BB\&BTB cho thấy BĐKH đã và đang có những tác động bất lợi đến cơ sở hạ tầng và diện tích nuôi ven biển. Nếu không có các giải pháp thích ứng thì $\mathrm{BĐKH} \mathrm{sẽ} \mathrm{gây} \mathrm{thiệt} \mathrm{hại} \mathrm{rất} \mathrm{lớn} \mathrm{cho} \mathrm{khoảng} 10.234$ ha nuôi tôm của cả vùng BTB đến năm 2030 và khi nước biển dâng lên $1 \mathrm{~m}$ thì khoảng 4.505 ha diện tích nuôi tôm của vùng sẽ bị ngập hoàn toàn. Khoảng $22,8 \%$ số xã nuôi tôm của vùng BTB có hệ thống điện bị thiệt hại do $\mathrm{BĐKH;} 22,4 \%$ số xã có đường trục xã, liên xã kết nối với vùng nuôi tôm bị ảnh hưởng; $22,3 \%$ số xã có đường trục trong thôn được nhựa/bê tông hóa bị thiệt hại; 20,1\% số kilomet kênh mương thủy lợi trong các vùng nuôi chưa được kiên cố hoá bị sạt lở hoặc cuốn trôi; 20,2\% số kilomet kênh mương đã kiên cố hóa nhưng vẫn bị sạt lở và $22,5 \%$ số trạm bơm nước phục vụ sản xuất NTTS trên địa bàn các xã có nuôi tôm bị hư hỏng do lụt bão.

Đóng góp của tác giả: Xây dựng ý tưởng nghiên cứu: H.N.K., T.T.T.H.; Lựa chọn phương pháp nghiên cứu: H.N.K.; Xử lý số liệu: H.N.K., T.T.T.H.; Viết bản thảo bài báo: H.N.K., T.T.T.H.; Chỉnh sửa bài báo: H.N.K.

Lời cảm ơn: Nghiên cứu này là kết quả của đề tài nghiên cứu khoa học cấp Quốc Gia, mã số BĐKH.18/16-20.

Lời cam đoan: Tập thể tác giả cam đoan bài báo này là công trình nghiên cứu của tập thể tác giả, chưa được công bố ở đâu, không được sao chép từ những nghiên cứu trước đây; không có sự tranh chấp lợi ích trong nhóm tác giả.

\section{Tài liệu tham khảo}

1. Perry, A.L.; Low, P.J.; Ellis, J.R.; Reynolds, J.D. Climate change and distribution shifts in marine fishes. Sci. 2005, 308, 1912-1915. https://doi.org/10.1126/science.1111322.

2. Brierley, A.S.; Kingsford, M.J. Impacts of climate change on marine organisms and ecosystem. Curr. Biol. 2009, 19, R602-R614.

3. Cheung, W.W.W.L.; Lam, V.W.Y.; Sarmiento, J.L.; Kearney, K.; Watson, R.; Zeller, D.; Pauly, D. Large-scale redistribution of maximum fisheries catchpotential in the global ocean under climate change. Glob. Change Biol. 2010, 16, 24-35. https://doi.org/10.1111/j.1365-2486.2009.01995.x 
4. Seggel, A.; de Young, C. Climate change implications for fisheries and aquaculture, Summary of the findings of the Intergovernmental Panel on Climate Change Fifth Assessment Report, Food and Agriculture Organization of the United Nations, 2016.

5. Harmeling, S. Global climate risk index 2012: Who suffers most from extreme weather events? Weather-related loss events in 2010 and 1991 to 2010 . Bonn, Germany: Germanwatch; 2012, pp. 28.

6. De Silva, S.S.; Soto, D. Climate change and aquaculture: potential impacts, adaptation and mitigation. In: Cochrane K.,C. De Young, D. Soto and T. Bahri (eds.), Climate change implications for fisheries and aquaculture: overview of current scientific knowledge, FAO Fisheries and Aquaculture Technical Paper No. 530, FAO, Rome, 2009, pp.156-212.

7. Kam, S.P.; Badjeck, M.C.; Teh, L.; Tran, N. Autonomous adaptation to climate change by shrimp and catfish farmers in Vietnam's Mekong River delta. WorldFish, Penang, 2012.

8. Badjeck, M.C.; Allison, E.H.; Halls, A.S.; Dulvy, N.K.;. Impacts of climate variability and change on fishery-based livelihoods. Mar. Policy 2010, 34, 375-383. https://doi.org/10.1016/j.marpol.2009.08.007.

9. Quyen, C.L. Study on climate change impacts on brackish water shrimp farming in coastal areas of Thanh Hoa province, Viet Nam. Doctor thesis, Hanoi 2016, pp.12.

10. Wood, C.M.; McDonald, D.G. Global warming: implications for fresh water and marine fish. Cambridge, UK. Cambridge University Press, 1997, pp. 425.

11. Jobling, M. Temperature and growth: modulation of growth rate via temperature change. In C.M. Wood, \& D.G. McDonald, eds. Global warming: implications for fresh water and marine fish, Cambridge, UK. Cambridge University Press, 1997, pp. $225-253$.

12. Rombough, P.T. The effects of temperature on embryonic and larval development. In C.M. Wood \& D.G. McDonald, eds. Global warming: implications for fresh water and marine fish. Cambridge, UK. Cambridge University Press, 1997, pp. 177-223.

13. Van der Kraak, G.; Pankhurst, N.W. Temperature effects on the reproductive performance of fish. In C.M. Wood \& D.G. McDonald, eds. Global warming: implications for fresh water and marine fish. Cambridge, UK. Cambridge University Press, 1997, pp. 159-176.

14. Sharp, G.D. Future climatic change and regional fisheries: a collaborative analysis. Rome. FAO. FAO Fisheries Technical Paper, No. 452, 2003, pp. 75.

15. Handisyde, N.T.; Ross, L.G.; Badjeck, M.C.; Allison, E.H. The effects of climate change on world aquaculture: a global perspective. Final Technical Report, DFID Aquaculture and Fish Genetics Research Programme, Stirling Institute of Aquaculture, Stirling, U.K. 2006, pp. 151. Available online: https://pdfs.semanticscholar.org/6626/1bf2b8624c4d1d2d9431f2067bbbf93780c0.p df.

16. Hanh, P.T.T.; Furukawa, M. Impact of sea level rise on coastal zone of Vietnam, Bulletin-College of Science University of the Ryukyus, 2007, 84, pp. 45.

17. Dasgupta, S.; Laplante, B.; Meisner, C. et al. The impact of sea level rise on developing countries: a comparative analysis. Clim. Change 2009, 93, 379-388. https://doi.org/10.1007/s10584-008-9499-5.

18. Hoang, N.V. Viet Nam's catfish and marine shrimp production: an example of growth and sustainability issues. Aquacul. Asia Pac. 2007, 3, 36-39.

19. How, Thu L. 2008. Adapting to global warming. Outlook, Viet Nam News Monthly Publication, 2008, 51, 8-11.

20. IPCC. Climate change 2014: synthesis report. Inter-Governmental Panel on Climate Change, 2014. Available online: https://www.ipcc.ch/report/ar5/syr/. 
21. Nghị quyết số 25/2015/NQ-HĐND ngày 18/12/2015 của Hội đồng nhân dân thành phổ về việc thông qua Quy họach phát triển kinh tế thủy sản cùa thành phố Hải Phòng giai đoạn 2016-2025, định hướng đến năm 2030, 2015.

\title{
The assessment of sea-level rise impacts due to climate change on aquaculture areas in the North and Central Coast in Vietnam
}

\author{
Hoang Ngoc Khac ${ }^{1,2 *}$, Tran Thi Thanh $\mathrm{Hai}^{2}$ \\ 1 Hanoi University of Natural Resources and Environment; hnkhac@hunre.edu.vn; \\ 2 Vietnam Institute of meteorology, hydrology and climate change; \\ haitran84@gmail.com;
}

\begin{abstract}
Aquatic products, includes both aquatic exploitation and aquaculture, are of paramount importance in global society and economy. Global climate change along with sea-level rise (SLR), on the other hand, has been affected directly and indirectly to the economy, agriculture, industry, and living habitats, especially in the coastal areas. Aquaculture productions in the North and North Central area of 11 coastal provinces in Vietnam play an important role in gross national income and food. Therefore, it is an imperative need to assess the impacts of climate change and sea-level rise on aquatic development in the research area. The study has collected and analyzed data of two sealevel rise scenarios (SLR $50 \mathrm{~cm}$ and SLR $100 \mathrm{~cm}$ ) and aquatic status of 11 provinces for impact assessment and propose the optimal solutions in response to climate change and sealevel rise. The results of two SLR scenarios show a relatively high potential of inundation with more than $50 \%$ of aquaculture areas, especially at the North e.g Nam Dinh, Thai Binh, and Thua Thien Hue in the North Central. The other provinces in the North Central seem to be less affected compared to areas in the North, especially at least in Ha Tinh and Quang Binh provinces. The climate-smart fisheries and aquaculture approaches which are being slowly implemented, though on small scales, show effective results in aquaculture development for those coastal areas.
\end{abstract}

Keywords: Aquatic; Aquaculture; Climate change; Climate-smart aquaculture; Sea-level rise. 